\title{
Vivir en (dis)continuidad: reconfiguración de subjetividades \\ religiosas en una comunidad ikojts de Oaxaca
}

\author{
LAURA MONTESI
}

\begin{abstract}
En la comunidad ikojts de San Dionisio del Mar, Oaxaca, las subjetividades religiosas viven entre tradiciones en apariencia divergentes y se reconfiguran alrededor de (dis)continuidades. Tanto católicos como protestantes usan los topoi de la modernidad y la tradición según circunstancias contingentes que demandan ahora confrontación, ahora negociación. En este artículo exploro las múltiples formas en las que los ikojts moldean sus identidades religiosas mediante un juego en el que se mezclan incoherencias llenas de significado. El caso de los ikojts exige que el análisis de las conversiones religiosas no se polarice en torno a ruptura o continuidad, sino que incluya la posibilidad de la (dis)continuidad.
\end{abstract}

PALABRAS CLAVE: recomposición religiosa, conversiones, (dis)continuidad, modernidad, tradición

Living in (Dis)continuity: Reconfiguration of Religious Subjectivities in an Ikojts Community of Oaxaca

In the Ikojts community of San Dionisio del Mar, Oaxaca, religious subjectivities live in the midst of apparently divergent traditions and reconfigure themselves around (dis)continuities. Both Catholics and Protestants use the topoi of modernity and tradition depending on contingent circumstances that demand confrontation or negotiation. In this article I explore the multiple ways in which the Ikojts craft their religious identities through an ongoing play of meaningful inconsistencies. I show that the analysis of religious conversions should not polarize around break or continuity but include the possibility of (dis)continuity.

KEYWORDS: religious reconstitution, conversions, (dis)continuity, modernity, tradition 


\section{Octubre de 2010}

egresé de Juchitán, Oaxaca, con una gran sorpresa y la esperanza de haber elegido una buena radio. Me aproximé a la casa de Ta Juan, ${ }^{1}$ pude distinguir su voz enojada: "Debe estar regañando a su esposa", pensé. Pasé la puerta de la casa y saludé a Ta Juan y Na Carmen. Como siempre, estaban sentados él en una sillita y ella meneándose en su hamaca, ambos tejían la cinta de palma para sacar un poco de dinero y pasar el día: “¿Le traje una cosa de Juchitán!”. Abrí la bolsa y saqué la radio. Ta Juan quedó un poco perplejo y yo, al ver su expresión interrogativa, le expliqué que se trataba de un regalo: "Ah, entonces aquí lo guardo". Lo cubrió con un pañuelo para que no se empolvara y empezamos a conversar, como solíamos hacer.

Ta Juan amaba platicar acerca de las costumbres de su pueblo. Había sido una autoridad en San Dionisio del Mar. Como presidente municipal, había traído la energía eléctrica al pueblo a finales de la década de 1960. Lamentaba el olvido de muchos paisanos que ya no se acordaban de él y de su esfuerzo político en una época en la que el gobierno no mandaba ni un peso, a diferencia de la situación actual en la cual los cargos se han convertido en motivo de riqueza y acaparamiento de dinero. Me hablaba con aire severo y orgullo. La pobreza en la que vivía daba sentido a su testimonio de duro trabajo por el bien de la colectividad. Ta Juan hablaba mucho sobre los tiempos pasados, cómo se hacían las cosas cuando era pequeño y cómo la sociedad había perdido el respeto, la dimensión moral, que es todo un género en el contexto ikojts. Entre las manifestaciones existentes, el respeto se expresa también en el apego a las costumbres católicas, los rituales de la mayordomía, las celebraciones de Semana Santa, las peregrinaciones y los velorios. Las descripciones de Ta Juan eran muy elocuentes y abundantes en detalles.

A pesar de esto, Ta Juan llevaba ocho años alejado del catolicismo por haberse convertido al pentecostalismo. No percibía esta contradicción cuando hablaba de

$1 \quad$ Los nombres se han modificado para garantizar el anonimato. 
los santos y de la belleza de sus fiestas, ni cuando argumentaba su conversión. Él había decidido tomar el bautismo a los 76 años de edad a causa de una enfermedad. Después de la milagrosa sanación gracias a las oraciones de los hermanos, Ta Juan decidió ir a la iglesia pentecostal para dar gracias a Dios y pedir su aceptación como nuevo feligrés. A la pregunta de por qué seguía hablando de las costumbres católicas con tanto involucramiento, Ta Juan continuaba el hilo de sus historias diciendo: "Pues ahora ya no creo en los santos, pero antes sí, antes sí”. A veces regañaba a su esposa por no haber dejado "a su Satanás" y no haberse convertido.

\section{Julio de 2012}

Levanté el teléfono y desde mi casa en Italia le hablé a mi familia adoptiva en San Dionisio. Después de los saludos acostumbrados pregunté si sabían cómo estaba mi amigo Ta Juan: “¿Acaso lo has soñado?”; "No, ¿por qué?”; "Pues hace un mes que murió".

\section{Septiembre de 2013}

Recién llegada a la comunidad, después de casi tres años de ausencia, fui a una junta del pueblo en la que se pretendía celebrar la lucha del pueblo contra la construcción de un megaproyecto eólico en sus tierras comunales. Me senté junto a unas mujeres a escuchar las palabras de los líderes del movimiento. Una señora se acercó y me preguntó si yo era Laura, "la muchacha de la radio". Con sorpresa, contesté que sí. Rosa se presentó, era la nuera de Ta Juan. Me comentó que, a la muerte del señor, lo enterraron con la radio en la caja para que se la llevara consigo. Ta Juan siempre mencionaba que yo se la había regalado y escuchaba las noticias de política transmitidas por una estación de Juchitán. Sentí una emoción fuerte. Le pedí a Rosa que me llevara al panteón. Al día siguiente, fui a dejar flores y una veladora en la tumba.

\section{Diciembre de 2013}

Pedro, uno de los hijos de Ta Juan, se convirtió en una persona importante en mi vida. Durante mi estancia en San Dionisio, platicaba con él casi a diario sobre los más disparatados temas. En una de nuestras charlas, Pedro me relató la muerte de su padre y cómo se despidieron de él:

Cuando mi papá [Ta Juan] falleció, mi hermano [evangélico] quería que [el funeral] se hiciera [según] la religión evangelio, él no quería que se llevaran flores ni nada. Ellos [los evangélicos] no hacen nada. Ya nos reunimos nosotros hermanos. Éramos siete. Por mayoría de votos decidimos que tenemos que hacer lo que es la costumbre aquí, católico, porque él fue católico, pues. Mi hermano nos apoyó, nos dio un apoyo moral, pero económico no colaboró, dijo que su religión no lo permite. Pero sí estuvo ahí con nosotros en los movimientos, buscando la res, buscando el señor que iba a matar la res, los que van a hacer los preparativos, estuvo apoyando, ahí estuvo con nosotros [...]. Mi papá nunca dejó totalmente a su religión. Cuando se convirtió, ya iba al templo: “¿Y ahora qué?”, le digo, “¿Ya cambiaste de religión?”. "No, pues voy a escuchar [la Palabra de Dios] los domingos". Pero él, cuando nosotros hacemos algo, un cumpleaños aquí, él viene. Hay música y él viene con mi mamá. A veces hacemos así, pagamos una misa, algo así, ¡viene él! A veces se iba a la iglesia [católica], llevaba como chagola, ${ }^{2}$ a veces va una persona mayor de edad con una

Término de origen zapoteca que se refiere a un experto ritual, por lo general anciano, que preside las ceremonias religiosas y del ciclo vital. 
vasija con flores y vela o veladora, entrega a la iglesia cuando hay una promesa y cuando la promesa es entre nosotros, él va, él lleva la flor, y él va a la iglesia a platicar con los señores [los encargados de la iglesia]: "Mira tal día se va a hacer esto", participar pues, y él va y también va a su templo [pentecostal]. Y así. Nunca dejó definitivamente lo que es su religión con que nació. Siempre un vecino o un pariente que haga una fiesta, él va. Aunque si sus compañeros allá le dicen que por qué va: "Pues yo ya fui mundano", diría él, "ya hice pachanga, ya la gente lo visitó, usted ya tiene que visitarlo, no es que yo quiera sino es que debo a la gente, tengo que ir, voy a dejar mi limosna, voy un rato". Nunca dejó su religión.

\section{Introducción ${ }^{3}$}

La figura de Ta Juan y su trayectoria biográfica epitomizan de manera elocuente la complejidad del campo religioso huave, ${ }^{4}$ que se caracteriza por fluidez, ambigüedades, contradicciones e incoherencias llenas de significado. En este artículo intento presentar las subjetividades religiosas de la comunidad de San Dionisio del Mar y comprender cómo una trayectoria biográfica como la de Ta Juan, lejos de ser excepcional y única, nos habla de cómo los ikojts viven las dinámicas sociales que han conducido a la transformación y pluralización de la religiosidad. Las siguientes páginas ofrecen una serie de reflexiones que nos llevan a apreciar la recomposición de las identidades religiosas como estrategia social de respuesta frente a un mundo en cambio, la confrontación y negociación entre estas identidades que van formando una comunidad plural, y sin embargo, dotada de cierta cohesión, y la demora de las subjetividades religiosas en espacios caracterizados por (dis)continuidades.

Como bien señalan Moreno y Castellanos, después de que en los años sesenta y setenta del siglo pasado los estudios sociológicos sobre lo religioso pronosticaran su derrumbe, dados los procesos de secularización y globalización, en las décadas siguientes la religión dejó de ser interpretada como un fenómeno residual destinado a la extinción y volvió a ser eje central de interés. Se impuso entonces la idea de la recomposición religiosa, que permite apreciar la complejización del campo religioso (Moreno y Castellanos, 2011: 7). Este concepto es el que mejor capta las transformaciones individuales y sociales que suceden entre las subjetividades religiosas y que, en el ámbito latinoamericano, permiten tomar en consideración no sólo la avanzada de las "nuevas" alternativas religiosas de corte evangélico, sino también el mundo católico, con frecuencia representado como en crisis.

Este artículo se basa en mi primera experiencia de trabajo de campo en San Dionisio del Mar, un mes en 2009 y cuatro en 2010, como parte de mi investigación de maestría. Durante este tiempo me dediqué al análisis de los censos de población y de pertenencia religiosa municipales y nacionales, de 1940 a 2010. Mapeé las iglesias protestantes en la comunidad, participé en la vida religiosa de dos grupos pentecostales, asistí a cultos, grupos de oración, festivales, campañas de evangelización, noches de alabanza, etc. Realicé entrevistas libres y semiestructuradas, recolecté historias de vida, organicé un grupo focal con jóvenes de 15 a 20 años de edad para explorar sus experiencias personales y opiniones acerca de su participación en la vida de la iglesia. La siguiente estancia, de un año, entre 2013 y 2014, como parte del doctorado, me permitió dar seguimiento a esta investigación, aunque la religiosidad cristiana no fuera el tema central.

$4 \quad$ Los huaves son un grupo étnico mexicano conformado por comunidades asentadas a lo largo de la costa del océano Pacífico en el Istmo de Tehuantepec, estado de Oaxaca. "Ikojts" -literalmente, "nosotros"- es el etnónimo en lengua indígena que denomina a los huaves de la comunidad de San Dionisio del Mar. El municipio cuenta con 5098 habitantes, según el Censo de Población y Vivienda 2010 (INEGI, 2010). Los ikojts se dedican principalmente a la pesca y al campo -siembra de maíz para autoconsumo y de ajonjolí y sorgo para comercialización-, en menor medida a la caza y a la ganadería. En los últimos 30 años ocurrió una diversificación de las actividades laborales que ha ido incluyendo trabajo informal, estacional, y migración interna y hacia Estados Unidos. 


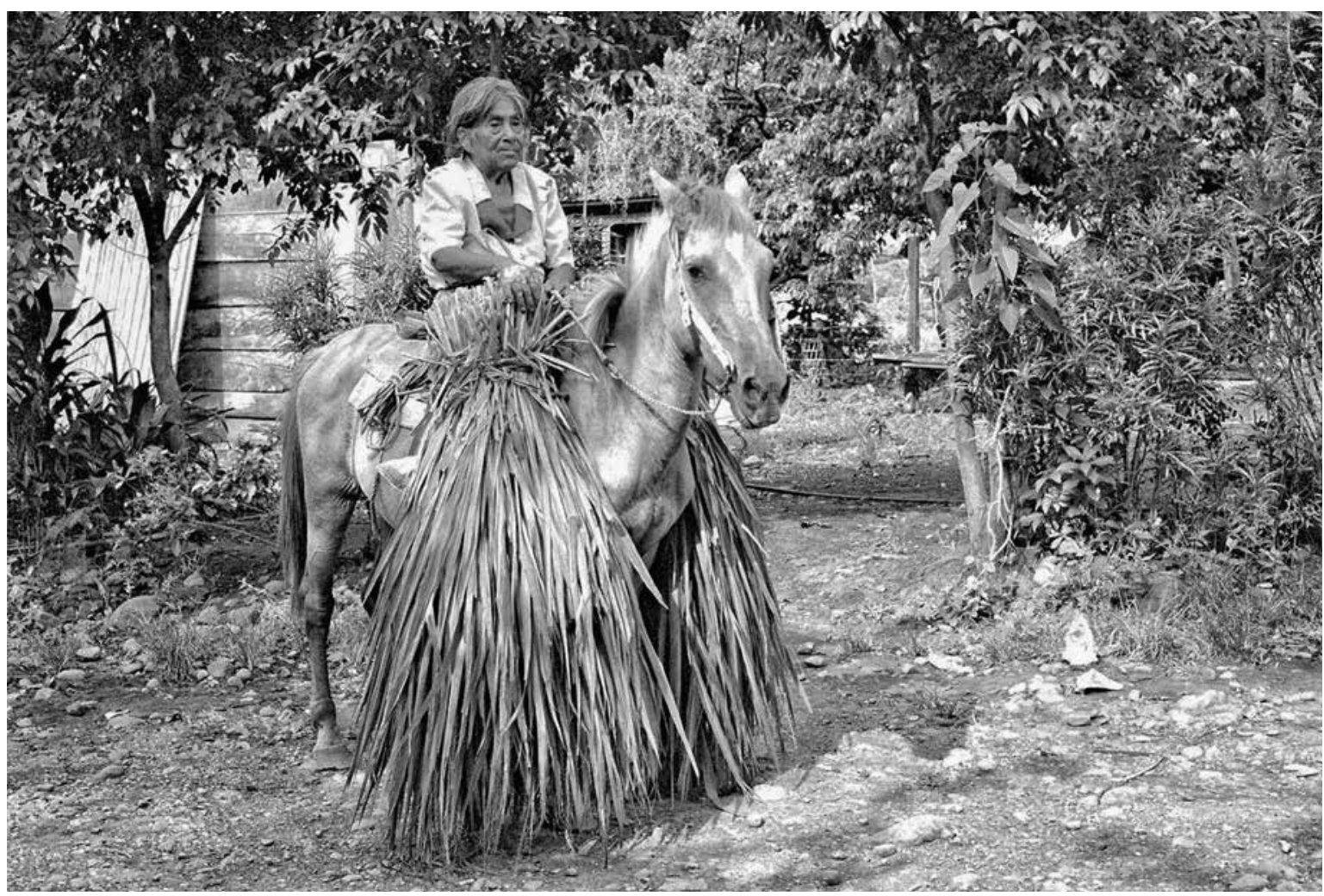

Consuelo Pagaza • Habitante de la Sierra de San Andrés Tuxtla. Veracruz, México, 2004.

A pesar de que la noción de recomposición apunta al dinamismo del fenómeno religioso, buena parte de los estudios antropológicos acerca de las conversiones en el marco del mundo cristiano ha llegado a construir modelos bidimensionales de la religión, que contraponen tradición y modernidad, o continuidad y discontinuidad. Por esta razón, he querido destacar, por medio del caso de la comunidad indígena ikojts de San Dionisio del Mar, cómo las incoherencias y ambivalencias en la vida de los sujetos religiosos son más la regla que la excepción y son precisamente ellas las que permiten ajustes y negociaciones en el campo social.

Es importante considerar que los cambios religiosos que se viven en San Dionisio del Mar desde los años sesenta del siglo pasado deben ser localizados en acontecimientos más amplios, de tipo social, económico y político, que presentan una compleja multidimensionalidad y han desatado profundos procesos de reconstrucción identitaria. Las conversiones religiosas responden, por lo tanto, al juego de poder de individuos llamados a actuar sobre las determinantes sociales que los ponen en condiciones de debilidad, vulnerabilidad, insatisfacción. Habiendo introducido el tema del poder, y antes de presentar el panorama religioso ikojts, es necesario aclarar brevemente por qué utilizo la fórmula "campo religioso" para indicar la expresión de las identidades religiosas, sus procesos de transformación, interacción e institucionalización. El concepto de campo es, claramente, de tipo bourdieuano. Para Bourdieu, el campo social es un espacio en el cual se posicionan sujetos dotados de puntos de vista particulares. Estos puntos de vista se caracterizan 
por derivar de una determinada posición dentro del espacio (Bourdieu, 1989: 18). Desde estas posiciones, los sujetos, dotados de una aprehensión activa del mundo, construyen su propia cosmovisión, pero siempre bajo los vínculos determinados por las constricciones estructurales (Bourdieu, 1989: 18). De esta manera, la sociedad se erige en tres movimientos: "como estructura estructurada históricamente; como estructura capaz de estructurar las prácticas sociales y las relaciones de poder; como estructura abierta a las transformaciones, es decir, con capacidad de ser estructurable por las luchas de poder emprendidas por los actores sociales" (De la Torre, 2002).

Estos mismos movimientos tienen lugar en el campo religioso, pero la aprehensión del mundo pasa a través de las creencias en relación con un orden sobrenatural y la fe se constituye como una experiencia fenomenológica que mueve y plasma a los sujetos y hace desprender la acción. El poder que condiciona estas posiciones hace aterrizar lo religioso dentro de un marco de producción y contestación del poder que se manifiesta en las más diminutas interacciones de la cotidianidad. Por esta razón, la religión, con sus manifestaciones, no puede ser abarcada como un mundo de significados cerrado, sino como un fenómeno cultural frente a la intersección de cuestiones de identidad étnica y procesos políticos y sociales dotados de profundidad histórica.

\section{Comunalidad y catolicismo indígena}

El papel desempeñado por la religión en la configuración de las comunidades indígenas de México ha sido esencial históricamente, desde la imposición del catolicismo por parte de los conquistadores, hasta su apropiación autonómica por los mismos pueblos originarios. Como señala Masferrer: "la desestructuración de las religiones indígenas permitió la construcción de lecturas étnicas del catolicismo colonial" (2000: 23), y esto hizo posible que Nueva España, luego México, pudiera formar su identidad a partir de una asunción nominal de la fe. A lo largo del proceso colonial y poscolonial, las comunidades indígenas entraron en un proceso de resistencia que les permitió recortar espacios de relativa autonomía por medio de prácticas comunitarias propias que se sedimentaron y formaron identidades. En tiempos recientes, algunos intelectuales indígenas oaxaqueños produjeron un corpus de literatura que teoriza y valora, en un esfuerzo epistemológico, las prácticas comunitarias indígenas que se presentan como diferentes y alternativas al proyecto civilizatorio occidental formulado por los grupos hegemónicos del Estado-nación mexicano. Estas prácticas moldean la "comunalidad", que si bien debería entenderse más como camino hacia la autodeterminación, ejercicio de socialidad y proyecto político-identitario, que como noción, también tiene su propia definición. Según Díaz, los elementos que definen la comunalidad son "la Tierra, como Madre y como territorio; el consenso en Asamblea para las tomas de decisiones; el servicio gratuito, como ejercicio de autoridad; el trabajo colectivo, como un acto de recreación; los ritos y ceremonias, como expresión del don comunal" (2007: 40).

Todos los elementos mencionados por Díaz están estrechamente vinculados a la religiosidad católica indígena que se manifiesta en lo institucional y político con el sistema de cargos, ${ }^{5}$ en la praxis cotidiana con el tequio, la mano vuelta, los cuidados a los santos y a la salud, etc.; y en lo ceremonial, con las festividades ligadas al santoral. El sistema de cargos, aunque también exista en algunas comunidades

\footnotetext{
5

"El sistema de cargos es un conjunto de jerarquías rituales o rituales-civiles, típico de las comunidades campesinas en Mesoamérica. Los oficios están ligados a los santos de la Iglesia Católica Romana" (Rhum, 1997: 50). [La traducción es mía.]
} 
que se consideran mestizas y urbanas, se presenta como una estructura eminentemente indígena que ha garantizado el ejercicio de la autonomía. Al definirla como indígena, no queremos vehicular una idea esencialista de la tradición sino poner énfasis en el papel identitario que este sistema ha jugado a lo largo del tiempo. ${ }^{6}$

San Dionisio del Mar no es excepción en el panorama mesoamericano. Muchas de sus prácticas comunitarias se moldearon sobre el sistema de cargos, las cofradías, las mayordomías y el ciclo ceremonial católico. A lo largo de los siglos, la vida religiosa ikojts no fue ajena a los acontecimientos y turbulencias políticas de la nación. Aquí las cofradías desempeñaron un papel fundamental en la comunidad (Millán, 2007: 48) hasta que la secularización del campo religioso, el alejamiento de los dominicos y el oleaje liberal del Estado mediante las Leyes de Reforma (1856-1857) provocaron su desaparición y el consiguiente surgimiento de las mayordomías, que se encargaron de sostener las actividades ceremoniales del pueblo. San Dionisio del Mar logró mantener una parte del "principal" —el dinero- de las cofradías (Frey, 1982: 29), de manera que "[a]unque los principales de los Santos nunca llegaron a recuperar la importancia material que tenían antes de la reforma, la tradición sobrevivió los disturbios sociales y económicos de siglos" (Frey, 1982: 29). Con el tiempo, las mayordomías se ajustaron y recompusieron: algunas se perdieron y otras surgieron. Este tipo de dinámica se registra también en la actualidad. A pesar de la fuerte secularización del poder, que se aceleró de manera significativa con la adopción del sistema político partidista y el desmembramiento de la estructura cívico-religiosa, con la declinación del escalafón civil y el mantenimiento del religioso, nos hace descartar la hipótesis de un derrumbe del mundo ceremonial católico (Montesi, 2012).

Los cambios estructurales, que se verifican en las comunidades rurales e indígenas de México bajo la influencia del capitalismo y del orden global junto a la reconfiguración del campo religioso con la avanzada de las alternativas de corte protestante, han hecho pensar que las instituciones tradicionales con sus lógicas comunitarias basadas en la reciprocidad estuvieran viviendo una crisis irreversible. No obstante que esta lectura tenga su razón de ser y el individualismo social y político esté cambiando el rostro de las comunidades locales, la complejidad de este panorama nos indica que, a pesar de que el debate sobre la naturaleza redistributiva o estratificadora del sistema de cargos y de las ceremonias católicas indígenas sea valioso, tal vez la oposición rural/urbano, comunidad/nación, nivelación/estratificación, ha sido demasiado polarizada y no ha permitido captar en pleno la multidimensionalidad de los procesos sociales que se desarrollan en los espacios comunitarios y en torno a la religión. Como bien señalan Salas Quintanal, Rivermar Pérez y Velasco Santos, el espíritu calculador, el espíritu de uso y el espíritu de reciprocidad no son prerrogativa excluyente de la sociedad rural o capitalista, ya que coexisten muy a menudo (2011: 13), aunque entren en conflicto en ciertas condiciones.

Esta clarificación es esencial al momento de abarcar el tema del cambio religioso y de las conversiones del catolicismo al protestantismo. De hecho, en la tentativa de explicar el avance protestante en las comunidades indígenas, se ha delineado una lectura del campo religioso indígena basada en la oposición binaria entre tradición - catolicismo-y economía de subsistencia, por un lado, y protestantismo y economía capitalista, por el otro. Esta visión necesita ser revisada.

6

La literatura que trata el tema de la naturaleza, los orígenes y los cambios del sistema de cargos es extensa. Véanse, por ejemplo, Cancian (1965); Carrasco (1961); Chance y Taylor (1985); Foster (1987); Nash (1958); Signorini (1982); Smith (1977); Terán (1995). 


\section{Recomposición religiosa: cirrupción de la modernidad en la costumbre?}

La avanzada de las alternativas religiosas de inspiración protestante en el mundo y en México ha hecho, justamente, que surjan preguntas acerca de la naturaleza de estas propuestas religiosas. Como hemos visto en el contexto mexicano, el catolicismo tiene un vínculo muy profundo con la historia de la nación y de las comunidades locales, mestizas e indígenas. Cuando nuevas identidades irrumpen en el panorama y cuestionan la tradición, se crea un conflicto según las líneas de un enfrentamiento de posiciones dentro del campo de poder. En efecto, en las comunidades indígenas, las conversiones del catolicismo a las formas heterogéneas de protestantismo no significan sólo un cambio de fe, sino algo más profundo: el abandono de todo un conjunto arraigado de prácticas sociales codificadas y de obligaciones comunitarias cuya atemperación determinaría la inserción y el mantenimiento de la vida individual dentro del desempeño de los roles tradicionales (Bartolomé, 1997: 137), y por fin, el fortalecimiento de la misma identidad comunitaria y étnica. Además, Latinoamérica se caracteriza por una vinculación significativa entre la Iglesia y los movimientos populares sociales y políticos bajo el marco de la opción preferencial por los pobres. En México, desde finales de la década de 1970, la Iglesia católica ha ejercido una importante influencia social que se ha manifestado en posiciones políticas dentro de contextos de conflicto, como es el caso del levantamiento neozapatista en Chiapas, respaldado por la diócesis de San Cristóbal de Las Casas, o del movimiento coceísta en Juchitán de Zaragoza, que tuvo un interlocutor importante en la diócesis de Tehuantepec. ${ }^{7}$

Entonces, es posible argumentar que el catolicismo ha sido apropiado y resemantizado por muchas comunidades locales, sobre todo indígenas y rurales. Desde tiempos coloniales, los procesos sincréticos permitieron la adaptación del calendario festivo católico al ciclo agrícola, lo que produjo ricas simbologías entre lo sobrenatural y el medio ambiente. Como analiza detenidamente Millán (1993), el calendario festivo de las poblaciones indígenas de Oaxaca está relacionado con las estaciones y las actividades económicas tradicionales, en el caso huave, con la agricultura y la pesca.

Las propuestas de inspiración protestante parecen promover discursos diferentes a los tradicionales, ponen énfasis en la experiencia individual de lo sagrado, niegan el poder de los santos, se alejan de las ceremonias religiosas que alimentan esa "relación materno-filial entre la tierra y nosotros, la gente" (Díaz, 2007: 52) y que convierte a la religiosidad algo concreto y simbólico (Díaz, 2007: 52). Esta ruptura, junto al nuevo dibujo de las relaciones de poder, ha determinado en muchos casos fuertes conflictos sociorreligiosos que han desembocado en violencia de varios grados en el estado de Oaxaca (Marroquín, 1995).

La emergencia del conflicto ha hecho que gran parte de la literatura sobre el cambio religioso interpretara la relación entre católicos y grupos protestantes en términos de "discontinuidad". Esta propuesta interpretativa es muy valiosa al menos por dos motivos importantes: 1) los mismos actores del campo religioso emplean la terminología de la ruptura - tanto los protestantes, por medio de la retórica de la conversión, como los católicos, en la descripción del conflicto en la comunidad-; 2) el estudio del campo religioso por parte de científicos sociales revela cómo su pluralización deriva del surgimiento de nuevas identidades que entran en una disputa de poder que perjudica la cohesión social.

La discontinuidad manifestada y ritualizada por los grupos protestantes ha sido leída por varios

$7 \quad$ Para conocer de cerca el involucramiento de la Iglesia en el Istmo y en los movimientos populares, véase Muro González (1994: cap. 4). 
antropólogos (Annis, 1987; Dow, 2005; Dow y Sandstrom, 2001; Montes, 1995; Nutini, 2000) como la solución que un número creciente de actores sociales elige para salir de lógicas tradicionales y comunitarias que no permiten la entrada en la modernización y en la lógica capitalista. El espíritu individualista promovido por las iglesias y sectas protestantes estaría más en consonancia con el orden hegemónico basado en el capitalismo tardío y en la sociedad de consumo. ${ }^{8}$ La alternativa religiosa se configuraría, entonces, como un camino viable y en apariencia apolítico para salir del sistema de cargos y del ciclo ceremonial, para invertir el dinero sacado de los circuitos de reciprocidad en actividades lucrativas. Según las condiciones de los contextos locales, la conversión crearía identidades resistenciales que desafiarían a los cacicazgos — como en el célebre caso de la comunidad chiapaneca de San Juan Chamula - o identidades proyectuales que afirmarían valores ligados al éxito personal.

El mérito de estas lecturas está en la comprensión de que la transformación religiosa no puede entenderse fuera de un macrocontexto en el que lo local vive de, e interacciona con lo global, y en el que las respuestas a los cambios estructurales suceden tanto en los movimientos sociales con fuerte reivindicación política como en las conversiones religiosas que emplean modalidades discursivas apolíticas. Desde esta óptica, es evidente que el proceso de desagrarización, los cambios climáticos que hacen imprevisibles los ciclos agrícolas, las estrategias de pluriactividad adoptadas por las familias, los efectos de las políticas públicas contemporáneas en hogares rurales y campesinos imponen un reto importante al catolicismo indígena, que vive un divorcio entre sus ceremonias y sus actividades económicas y cosmovisión. ${ }^{9}$

Sin embargo, al enfocarnos sólo en los discursos y las prácticas de discontinuidad entre católicos y protestantes, quedamos con una visión parcial de una realidad social más compleja, que se caracteriza por contradicciones que coexisten sin poder o querer ser resueltas. El límite de las interpretaciones que polarizan catolicismo y protestantismo en términos de tradición versus modernidad, o economía de subsistencia comunitaria versus economía capitalista, está en lo siguiente: se priva a la tradición de una dimensión creativo-productiva; se alimenta una visión bifurcada de la historia fundada en un "antes" — cuando la comunidad indígena cerrada quedaba al margen del sistema mundo-y un "después" — cuando es devorada por la aldea global—; no se toma en cuenta que las mismas dinámicas de hegemonía son productivas y pueden tener un efecto contrario, es decir, de revitalización del catolicismo; ${ }^{10}$ se propone un modelo binario de conversión como un acomodamiento a la vida moderna, o al contrario, como una retirada (Cahn, 2003: 163164). Como lo han demostrado estudios recientes, en contextos diversos la religiosidad indígena tradicional se resemantiza y se convierte en un elemento que contribuye a la construcción de un "proyecto de comunidad" (González, 2011: 166); esto ocurre tanto en comunidades urbanas mestizas, como Jesús Tepactepec, Nativitas, Tlaxcala (González, 2011) o San Andrés Cholula, Puebla (Velasco,

8 Para un análisis contundente de la relación entre posmodernidad, mercado y religión contemporánea, véase el número 18 de Desacatos, coordinado por Renée de la Torre y Cristina Gutiérrez Zúñiga (2005).

9 Montes (1995) relaciona la crisis del campo agrícola mexicano con la crisis del catolicismo indígena.

10 En fechas recientes, la comunidad zapoteca de Álvaro Obregón, agencia municipal de Juchitán, bajo la amenaza de la construcción de un proyecto eólico y después de las experiencias de lucha contra el despojo territorial, está en proceso de pasar del sistema partidista al de usos y costumbres. En septiembre de 2013, en San Dionisio del Mar se celebró una misa en la iglesia católica para conmemorar la lucha contra el proyecto. Éstos son ejemplos de cómo la inequidad de poder y el avance neoliberal en el ámbito local pueden determinar procesos de resurgimiento étnico acompañados de una valoración de la tradición y lo religioso. 


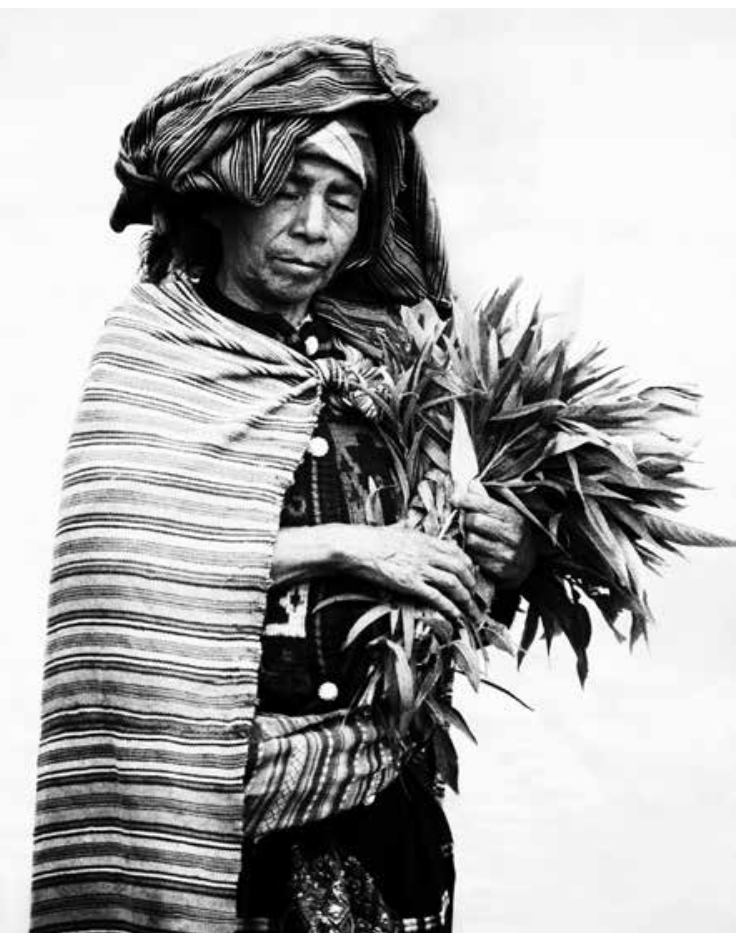

RICARDO RAMIREZ ARRIOLA/ARCHIVO360.COM • Mujer indígena guatemalteca en la bruma del amanecer camino al mercado, el día de la Consulta Popular sobre las Reformas Constitucionales. Totonicapán, Guatemala, 16 de mayo de 1999.

2011), como en rurales e indígenas. Además, surgen religiosidades transnacionales, como es el caso de algunos ikojts que emigraron a Oklahoma, Estados Unidos, y cada año organizan su propia celebración del patrón Dionisio el Areopagita. La recomendación es tener juntas las dimensiones de la discontinuidad y la continuidad para reconocer que las sujetividades del campo sociorreligioso se mueven con destreza en espacios caracterizados por ambigüedades y utilizan los topoi de la ruptura y la continuidad según sus intereses y objetivos, no siempre de manera consciente, para la construcción de sus identidades. El caso de San Dionisio del Mar, donde hasta la fecha protestantes y católicos han vivido de forma pacífica, nos permite reflexionar sobre cómo los espacios de (dis)continuidad son apropiados de manera plástica para poder jugar en el campo social.

\section{Fluidez religiosa en San Dionisio del Mar}

La diversificación del campo religioso en San Dionisio empezó en los años sesenta del siglo pasado, cuando la región ístmica fue objeto de una campaña de evangelización de movimientos pentecostales ya establecidos en Juchitán (Millán, 2010). El área huave había sido alcanzada por grupos protestantes y San Mateo del Mar fue la primera comunidad huave en conocer la segunda evangelización emprendida por los bautistas y la intervención del Instituto Lingüístico de Verano, en las décadas de 1930 y 1940. El censo de 1950 señala que en el municipio de San Dionisio del Mar había sólo dos hombres protestantes, mientras que en 1980 ya se contaban 47 personas convertidas, es decir, 1.27\% de la población total. Todavía era una minoría, pero constituía un grupo dotado de estructura. ${ }^{11}$ En la actualidad, ${ }^{12}$ los evangélicos representan 14\% de la población, lo cual constata un crecimiento acelerado en los últimos 30 años. En San Dionisio del Mar están presentes las siguientes denominaciones: nazarenos, Iglesia del Nazareno; pentecostales, Iglesia Primitiva, Casa Misión e Iglesia de Dios en México Evangelio Completo; adventistas del Séptimo Día, Casa Misión, y Testigos de Jehová.

Con sus matices, estos grupos producen discursos que promueven el desarrollo personal de los individuos, prometen el cambio ético y el pasaje de una vida triste, vacía, dominada por el vicio y la corrupción moral a una vida ascética; abogan por conductas rectas, fundadas sobre virtudes como obediencia, humildad, abnegación y trabajo; anuncian la cercanía del fin del mundo. Los mensajes que pretenden inculcar se presentan como universales y

Desafortunadamente, los datos sobre religión de los censos de 1960 y 1970 no están disponibles porque fueron recolectados por el distrito de Juchitán, y no por municipio.

12 
escatológicos. Los templos se configuran como sitios de socialización en los que el feligrés comparte las experiencias más importantes de su vida. Las instituciones presentan un espíritu totalizador y en su interior hay mecanismos que garantizan y reproducen el compromiso, la dedicación y cierto control social (Bowen, 1996). Esta visión del grupo y de la pertenencia requiere que el miembro de la iglesia se separe de prácticas y relaciones sociales asociadas a la tradición católica, definida como pagana o mundana: el evangélico no debe participar en las fiestas porque son lugar de vicio, debe considerarse hermano o hermana de los demás evangélicos y romper vínculos de compadrazgo con los católicos, debe quemar el altar y los santos que habitan las casas de cada familia, porque son sólo ídolos. Así, la discontinuidad y la ruptura son elementos fundamentales de cada conversión y los conversos privilegian esta dimensión en sus autorrepresentaciones en las campañas de evangelización que se llevan a cabo a lo largo y ancho de la comunidad y la región.

Los relatos de las conversiones pueden considerarse un verdadero género. Presentan patrones recurrentes y una estructura común que se adapta a las particularidades de cada trayectoria biográfica. Representan una retórica pública interiorizada, esencial en la construcción de las subjetividades (Stromberg, 1993). El habla y la narración, así como los sueños y las experiencias místicas, son herramientas experienciales por medio de las cuales se forman las comunidades evangélicas y adquieren una identidad propia frente a una mayoría católica, a la que desafían. Aquí surgen los conflictos, tanto en lo personal como en lo familiar y comunitario. No obstante que el papel de la ruptura sea central en la concreción de las identidades evangélicas, lo que se plantea aquí es que una observación más profunda de la realidad social y de las relaciones interpersonales revela un panorama en el cual los sujetos religiosos viven constantemente en espacios de ambigüedad y contradicción.
Empecé el artículo con la presentación de Ta Juan y mi relación en el tiempo con él y su familia porque me parecía que esto explicaría con elocuencia las (dis)continuidades de las trayectorias religiosas ikojts. Veamos su caso más de cerca. Ta Juan regañaba a su esposa por no haber querido convertirse. A pesar de las vehementes reprimendas, él seguía valorando su propio pasado, basado en la tradición y la costumbre del pueblo del cual fue máximo representante como presidente municipal y mayordomo. Las cosas del pasado pertenecían en sí al ayer, pero no eran objeto de desprecio o negación. Los santos habían sido su religión: ya no los veneraba, pero los seguía respetando. Sabía que eran ídolos, pero al mismo tiempo tenían su valor y su significado identitario profundo. Su hijo Pedro cuenta cómo los lazos de reciprocidad que su padre tenía con la gente nunca fueron interrumpidos sino ajustados por medio del compromiso. Antes de su conversión, Ta Juan recibió ayuda en forma de mano vuelta, apoyo y regalos, como se acostumbra en las comunidades indígenas oaxaqueñas. Ta Juan estaba en deuda y tenía que ser recíproco. Por eso, aunque fuera pentecostal, visitaba a sus compadres, dejaba su limosna e iba a las fiestas, aunque sus visitas fueran breves. Su muerte fue objeto de discusión. Los hijos, la mayoría católicos, decidieron que Ta Juan, a pesar de haberse convertido, no había dejado de ser aficionado a la tradición de su pueblo. El hijo pentecostal no dio su apoyo económico, pero participó activamente en todos los rituales de entierro y velorio. Ta Juan fue velado como de costumbre.

Las aparentes ambigüedades en las prácticas y las creencias relacionadas con la religión no son únicas de Ta Juan y su familia. De hecho, ejemplifican las diversidades religiosas en la cotidianidad de muchos ikojts. De esto hablan los casos de Na Simona, quien participa en los preparativos de la fiesta de su barrio en honor a la Candelaria, aunque es evangélica, y $\mathrm{Na}$ Luisa, enferma de diabetes, quien planea convertirse al evangelismo, pero después de haber cumplido su 
promesa: en cuatro años será mayordoma y organizará la celebración del santo patrón. Es como si $\mathrm{Na}$ Luisa tuviera dos identidades religiosas y su concepto de conversión estuviera proyectado en el tiempo.

Aunque la ruptura sea central en la autodefinición de los evangélicos que se presentan como nacidos por segunda vez en Cristo, también se matiza cuando la vida personal y social lo requiere. Varios antropólogos han explorado las estrategias por medio de las cuales los sujetos gestionan la ruptura con su propio pasado y entorno social con mediaciones que pueden ser de realineamiento (Engelke, 2010), no completamiento (Meyer, 1998) y preservación de ontologías espirituales indígenas mediante la demonización (Robbins, 2004).

Son muchos los casos que se pueden mencionar a favor de esta lectura de la realidad sociorreligiosa ikojts. Me limitaré a referir uno que considero significativo porque permite iluminar los procesos de negociación entre las partes y las dinámicas de rechazo y reinvención de la tradición. Se trata de los matrimonios mixtos. Cuando la concertación entre católicos y evangélicos es imprescindible, se abre un abanico de estrategias más o menos conciliatorias.

Una manera de resolver el problema del matrimonio mixto es dividir la celebración en dos: la civil y la religiosa. En muchos casos, la primera es festejada a la manera "protestante", es decir, con música cristiana y sin consumo de alcohol. La segunda, a la manera "católica", es una gran fiesta con grupo musical, baile y cerveza. Los dilemas de lealtad hacia una u otra religión se resuelven con un delicado juego de poder según los recursos de los sujetos en sus posiciones dentro del campo social: la familia de la novia ejerce presión y concede a la hija sólo bajo condiciones favorables para ella, mientras que la familia del novio cuenta con influencia para que la novia se instale en su grupo familiar, según las reglas de la residencia virilocal. Si la negociación no llega a una solución, entonces se deja que la pareja resuelva el problema con el paso del tiempo. En ese caso, se casará por el civil y después de meses o años tomará la decisión acerca de la boda religiosa.

En San Dionisio del Mar es una costumbre que el novio "robe" a la muchacha. Cuando esto ocurre, la mujer llega a casa del novio y es desflorada. La madrina se encarga de verificar la virginidad de la joven. Más tarde, la familia del novio visita a la de la novia con dos chagolas para hacer el compromiso de la boda. Si las familias tienen un acuerdo, seguirá el rito de la "amanecida", cuando la futura esposa recibe las visitas y los dones de parientes y vecinos. Aunque ya no sea muy común, si la muchacha no sale virgen, el novio tiene la facultad de rechazarla y regresarla a su casa. La robada ahora es cada vez más frecuente, ha ido sustituyendo a la pedida y fortaleciéndose como "tradición". Es posible suponer que la robada sea una costumbre zapoteca apropiada por los ikojts. En 1982, Rita señalaba que la valoración de la virginidad en la comunidad huave de San Mateo podía ser fruto del proceso de aculturación zapoteca (1982: 201).

En las iglesias evangélicas, la robada es considerada una práctica inmoral porque no cumple las formalidades consideradas importantes, como la presentación del novio a la familia de la muchacha y la solicitud del permiso para juntarse con ella. Aunque en la realidad muchos evangélicos roben a sus novias, las familias prefieren la pedida, lo que ha generado una reflexión sobre las relaciones de género. En algunos casos, las familias evangélicas pueden rechazar a los chagolas de la familia del novio y no querer conocer el estado de virginidad de la hija. De esta manera se van abriendo espacios inéditos de reforma de las relaciones de género. Esta reforma sigue las pautas de la (dis)continuidad con la costumbre. Me explicaré mejor.

En muchos contextos de Latinoamérica, las nuevas alternativas religiosas han ofrecido un espacio de empoderamiento o protección para las mujeres, tema señalado por varios autores (Brusco, 1995; Gill, 1990; Goldstein, 2003: 215-225; Montesi, 2013; 


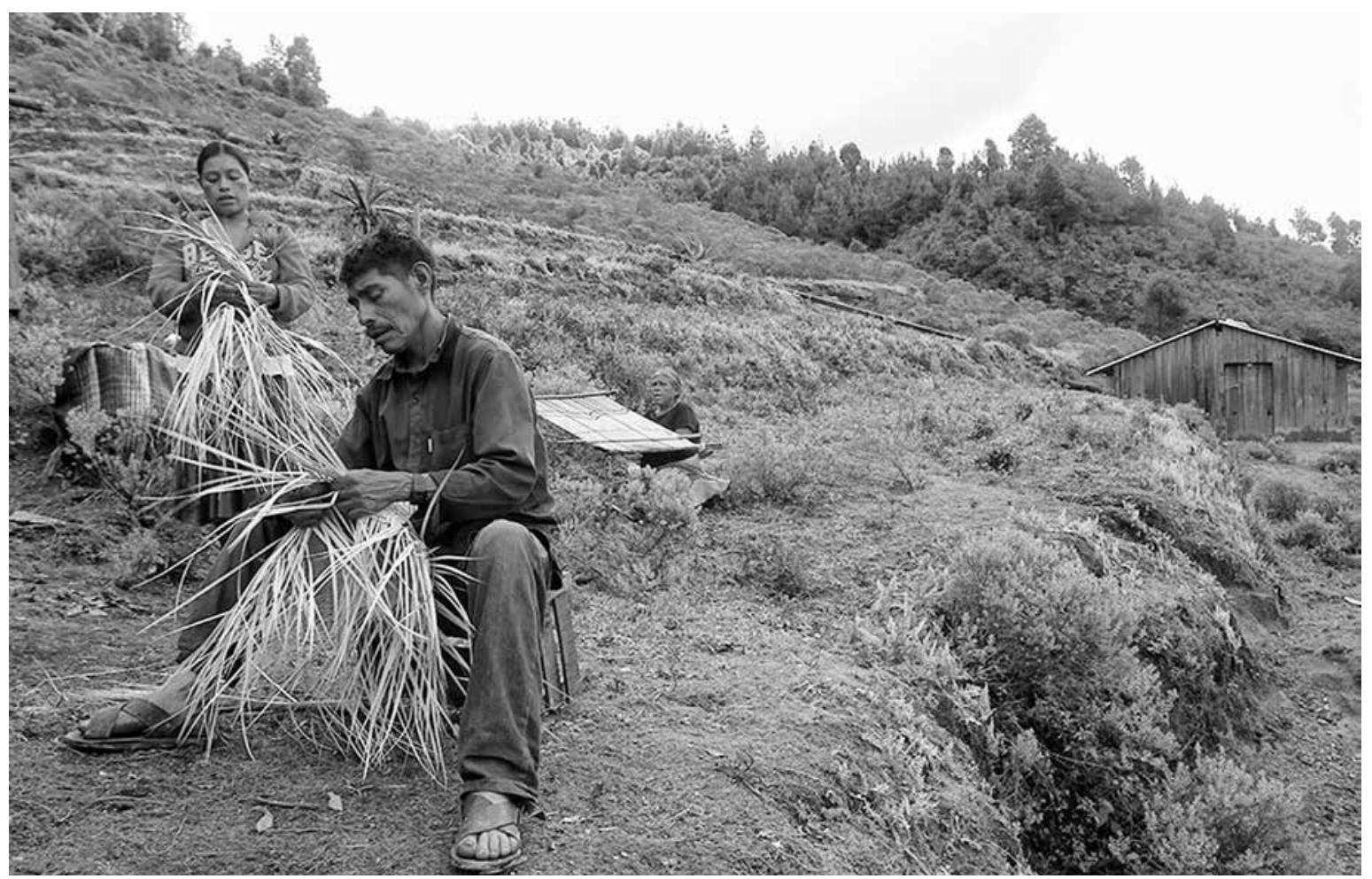

Consuelo Pagaza • Habitantes de San Miguel Amoltepec el Viejo, desplazados por la tormenta Manuel en 2013, elaboran sombreros de palma

y huipiles típicos de la zona. Cochoapa, Guerrero, México, 2014.

Rostas, 1999). A veces este empoderamiento surge a partir del rechazo a ciertas costumbres percibidas como moralmente incorrectas, es decir, de una ruptura con el orden. Tal es el caso de la oposición a la robada, práctica matrimonial definida como tradicional por los ikojts. A pesar de esta discontinuidad hablada y a veces actuada, los evangélicos proponen un realineamiento con otra tradición, una historia cristiana existente o imaginaria (Engelke, 2010: 179). En términos locales, esto se traduce en la preferencia por la práctica de la pedida, que pone en segundo plano la importancia de la virginidad, la cual no llega a ser objeto de elaboración ritual. A pesar de que las iglesias protestantes promuevan un rol ideal de la mujer basado en valores y virtudes tradicionales, como la fidelidad, el amor conyugal, las virtudes maternas y la obediencia, sus prácticas producen una profunda reforma de las relaciones de género, que abre espacios de ejercicio de poder femenino. Se rechaza una costumbre, la robada, y se revitaliza otra, la pedida.

Sin querer subestimar la importancia de los discursos de los actores sociales, quienes enfatizan la discontinuidad entre católicos y evangélicos, este ejemplo demuestra dos aspectos: que la cotidianidad requiere un ejercicio constante de negociación y compromiso, y que los cambios en la visión del mundo no pasan sólo por actos de resistencia, sino también, y sobre todo, por usos estratégicos de la(s) tradicion(es) y la(s) modernidad(es). Es importante reconocer que modernidad y tradición deberían ser vistos en términos plurales - hay muchas tradiciones y muchas modernidades-y más como recursos que se constituyen mediante procesos, que como 
realidades en sí. Católicos y protestantes reflexionan sobre los cambios del mundo en el que viven y recurren a los topoi de la tradición y la modernidad de distintas maneras para darle sentido a sus experiencias de vida y buscar formas de empoderamiento dentro de campos sociales caracterizados por relaciones de poder desiguales. La modernidad puede percibirse como amenaza o como respuesta, según los contextos, las temporalidades y espacialidades. La dicotomía entre modernidad y tradición analizada en el párrafo anterior puede ser útil, pero con facilidad termina siendo una camisa de fuerza, sobre todo cuando se pone el énfasis en los contenidos más que en los procesos.

Las iglesias protestantes, con sus contradicciones y discursos conservadores y apolíticos que coexisten con aspectos reformativos, ofrecen retos teóricos importantes: ¿cómo darle sentido y coherencia a sus ambigüedades? ¿Cómo es posible que religiosidades que rechazan la costumbre y promueven lo moderno lo hagan realineándose o inventando lo tradicional? ¿Por qué Ta Juan es un ferviente pentecostal y sigue amando la costumbre? ¿Cómo puede Na Luisa querer ser mayordoma del santo patrón cuando tiene planeado convertirse al evangelismo?

\section{Conclusiones: subjetividades ambiguas y (dis)continuas}

He intentado presentar en este espacio las múltiples subjetividades religiosas que se estructuran dentro del campo social y lo estructuran. Las experiencias religiosas que viven de lo místico y lo inexplicable se insertan en experiencias colectivas organizadas alrededor de núcleos de identidad. Estas identidades están en un diálogo constante con el mundo y vehiculan demandas de contestación al poder o de inscripción en él. Las estrategias sociales adoptadas frente a un mundo siempre más pluralizado, despedazado e interconectado no pueden más que ser múltiples (Montesi, 2012) y la recomposición religiosa no tiene que ver sólo con la avanzada de los grupos protestantes, sino también con la actualización del catolicismo indígena.

Los rostros de las identidades religiosas, aunque en apariencia se presenten bien definidos y propongan discursos que no ofrecen duda sobre sus características propias, habitan espacios dominados por ambigüedades y usos incoherentes pero llenos del significado de los topoi de la modernidad y la tradición. Los ikojts se convierten del catolicismo al protestantismo y viceversa, celebran a su santo en Estados Unidos, abandonan algunas mayordomías, pero crean grupos de festejo de las vírgenes regionales - la Juquila— y nacionales — Guadalupe-, se oponen a ciertas tradiciones - la robada - pero se realinean o reinventan otras - la pedida - y les confieren nuevos significados que responden a sus preocupaciones y necesidades.

Estas fluideces proponen retos importantes para los antropólogos, quienes "lidian con la cuestión de cómo caracterizar y explicar las subjetividades de interlocutores situados en medio y entre formas de vida aparentemente divergentes" (Holtzman, 2009: 251). [La traducción es mía.] De hecho, la oposición entre continuidad o discontinuidad en el campo religioso cristiano conlleva el riesgo de perder de vista cómo Ta Juan, Na Simona, Na Luisa y muchos más se mueven en un espacio de (dis)continuidades, donde lo moderno y lo tradicional se construyen, descomponen y reconstruyen según los contextos, y donde el compromiso y las ambigüedades parecen ser la regla más que la excepción.

De la misma manera, lo moderno y lo tradicional deberían ser abarcados con énfasis en los procesos más que en sus características intrínsecas. El uso de estos topoi se puede cristalizar en actos de aceptación o contestación ambivalentes. Las trayectorias religiosas ikojts sugieren que el estudio antropológico de la cristiandad se beneficiaría si fuera más allá de la oposición entre continuidad y discontinuidad, 
tradición y modernidad, y explorara — sin que esto ocasione desconcierto- los espacios contradictorios que los sujetos religiosos habitan.

Bajo estas consideraciones, me pregunto si Ta Juan estaría contento al enterarse de cómo fue enterrado y velado. Mi experiencia entre los ikojts me dice que, a pesar de ser pentecostal y haber recibido con alegría un segundo bautizo a los 76 años de edad, Ta Juan está feliz de haber pasado al otro mundo con todos los rezos necesarios, las bendiciones de san Dionisio el Areopagita y las visitas de las personas a las cuales ya no debe nada porque en vida, también después de la conversión, les siguió correspondiendo. D

\section{Bibliografía}

Annis, Sheldon, 1987, God and Production in a Guatemalan Town, University of Texas Press, Austin.

Bartolomé, Miguel Alberto, 1997, Gente de costumbre y gente de razón. Las identidades étnicas en México, Instituto Nacional Indigenista/ Siglo XXI Editores, México.

Bourdieu, Pierre, 1989, "Social Space and Symbolic Power", en Sociological Theory, vol. 7, núm. 1, pp. 14-25.

Bowen, Kurt, 1996, Evangelism and Apostasy: The Evolution and Impact of Evangelicals in Modern Mexico, McGill-Queen's University Press, Montreal.

Brusco, Elizabeth, 1995, The Reformation of Machismo: Evangelical Conversion and Gender in Colombia, University of Texas Press, Austin.

Cahn, Peter, 2003, All Religions are Good in Tzintzuntzan: Evangelicals in Catholic Mexico, University of Texas Press, Austin.

Cancian, Frank, 1965, Economics and Prestige in a Maya Community. The Religious Cargo System in Zinacantan, Stanford University Press, Stanford.

Carrasco, Pedro, 1961, "The Civil-Religious Hierarchy in Mesoamerican Communities: Pre-Spanish Background and Colonial Development”, en American Anthropologist, vol. 63, núm. 3, pp. 483-497.

Chance, John y William Taylor, 1985, "Cofradías and Cargos: An Historical Perspective on the Mesoamerican Civil-Religious Hierarchy", en American Ethnologist, vol. 12, núm. 1, pp. 1-26.

Díaz Gómez, Floriberto, 2007, "Comunidad y comunalidad”, en Sofía Robles Hernández y Rafael Cardoso Jiménez (comps.), Escrito. Comunalidad, energía viva del pensamiento mixe, Universidad Nacional Autónoma de México, México.

Dow, James, 2005, "The Expansion of Protestantism in Mexico: An Anthropological View", en Anthropological Quarterly, vol. 78, núm. 4, pp. 827-851.

Dow, James y Alan Sandstrom (eds.), 2001, Holy Saints and Fiery Preachers: The Anthropology of Protestantism in Mexico and Central America, Praeger, Westport.

Engelke, Matthew, 2010, "Past Pentecostalism: Notes on Rupture, Realignment, and Everyday Life in Pentecostal and African Independent Churches", en Africa: The Journal of the International African Institute, vol. 80, núm. 2, pp. 177-199.

Foster, George, 1987, Tzintzuntzan: Ios campesinos mexicanos en un mundo en cambio, Fondo de Cultura Económica, México.

Frey, Hans R., 1982, La jerarquía político-eclesiástica y la mayordomía en San Dionisio del Mar, Oaxaca, Oaxaca, Universidad Autónoma Benito Juárez de Oaxaca, Oaxaca.

Gill, Lesley, 1990, “'Like a Veil to Cover Them': Women and the Pentecostal Movement in La Paz”, en American Ethnologist, vol. 17, núm. 4, pp. 708-721.

Goldstein, Donna, 2003, Laughter Out of Place: Race, Class, Violence and Sexuality in a Rio Shantytown, University of California Press, Berkeley.

González de la Fuente, Î̃igo, 2011, “El sistema de cargos en una sociedad local urbanizada, industrializada y mestiza”, en Hernán Salas Quintanal, María Leticia Rivermar Pérez, Paola Velasco Santos (coords.), Nuevas ruralidades: expresiones de la transformación social en México, Universidad Nacional Autónoma de México, México.

Holtzman, Jon, 2009, Uncertain Tastes: Memory, Ambivalence, and the Politics of Eating in Samburu, Northern Kenya, University of California Press, Berkeley.

Instituto Nacional de Estadística y Geografía (INEGI), 1950, Séptimo Censo General de Población, Instituto Nacional de Estadística y Geografía, México. 
—_ 1980, X Censo General de Población y Vivienda, Instituto Nacional de Estadística y Geografía, México.

, 2010, Censo de Población y Vivienda 2010, Instituto Nacional de Estadística y Geografía, México.

Marroquín, Enrique (coord.), 1995, ¿Persecución religiosa en Oaxaca? Los nuevos movimientos religiosos, Instituto Oaxaqueño de las Culturas, México.

Masferrer Kan, Elio, 2000, Sectas o iglesias. Viejas o nuevas religiones, Plaza y Valdés, México.

Meyer, Birgit, 1998, “'Make a Complete Break With the Past': Memory and Post-Colonial Modernity in Ghanaian Pentecostalist Discourse”, en Journal of Religion in Africa, vol. 28, núm. 3, pp. 316-349.

Millán, Saúl, 1993, La ceremonia perpetua: ciclos festivos y organización ceremonial en el sur de Oaxaca, Instituto Nacional Indigenista, México.

__, 2007, El cuerpo de la nube. Jerarquía y simbolismo ritual en la cosmovisión de un pueblo huave, Instituto Nacional de Antropología e Historia, México.

__ 2010, “La costumbre amenazada. Procesos de transformación religiosa en el Istmo de Tehuantepec”, en Ella F. Quintal, Aída Castillejas y Elio Masferrer Kan (coords.), Los dioses, el evangelio y el costumbre. Ensayos de pluralidad religiosa en las regiones indigenas de México, t. III, Instituto Nacional de Antropología e Historia, México.

Montes García, Olga, 1995, “Los conflictos religiosos en Oaxaca: una aproximación a su estudio”, en Enrique Marroquín (coord.), ¿Persecución religiosa en Oaxaca? Los nuevos movimientos religiosos, Instituto Oaxaqueño de las Culturas, México.

Montesi, Laura, 2012, "La costumbre y el evangelio: estrategias múltiples de transformación religiosa entre los huaves de Oaxaca (México)", en Virajes, Revista de Antropología y Sociología, vol. 14, núm. 2, pp. 277-300.

__. 2013, "'But I don't want to leave the church! I like it!': Evangelical Discourses and Women's Empowerment in an Indigenous Huave Community (Mexico)", en Suomen Antropologi, Journal of the Finnish Anthropological Society, vol. 38, núm. 2, pp. 41-61.

Moreno Baptista, César y Juan Manuel Castellanos, 2011, “Editorial”, en Virajes, Revista de Antropología y Sociología, vol. 14, núm. 2, pp. 7-11.

Muro González, Víctor Gabriel, 1994, Iglesia y movimientos sociales en México, 1972-1987: Ios casos de Ciudad Juárez y el Istmo de Tehuantepec, Red Nacional de Investigación Urbana/El Colegio de Michoacán, Puebla.

Nash, Manning, 1958, “Political Relations in Guatemala”, en Social and Economic Studies, vol. 7, núm. 1, pp. 65-75.

Nutini, Hugo, 2000, "Native Evangelism in Central Mexico”, en Ethnology, vol. 39, núm. 1, pp. 39-54.

Rhum, Michael, 1997, "Cargo System”, en Thomas Barfield (ed.), The Dictionary of Anthropology, Blackwell, Cambridge.

Rita, Carla M., 1982, "Concepimento e nascita”, en Italo Signorini (coord.), Gente di laguna. Ideologia e istituzioni sociali dei Huave di San Mateo del Mar, Franco Angeli, Milán.

Robbins, Joel, 2004, "The Globalization of Pentecostal and Charismatic Christianity”, en Annual Review of Anthropology, vol. 33, pp. 117-143.

Rostas, Susanna, 1999, "A Grass Roots View of Religious Change Amongst Women in an Indigenous Community in Chiapas, Mexico", en Bulletin of Latin American Research, vol. 18, núm. 3, pp. 327-341.

Salas Quintanal, Hernán, María Leticia Rivermar Pérez y Paola Velasco Santos, 2011, "Introducción: espacio y comunidad en época de globalización”, en Hernán Salas Quintanal, María Leticia Rivermar Pérez y Paola Velasco Santos (coords.), Nuevas ruralidades: expresiones de la transformación social en México, Universidad Nacional Autónoma de México, México.

Signorini, Italo, 1982, “Il sistema di cargos civili e religiosi”, en Italo Signorini (ed.), Gente di laguna. Ideologia e istituzioni sociali dei Huave di San Mateo del Mar, Franco Angeli, Milán.

Smith, Waldemar R., 1977, The Fiesta System and Economic Change, Columbia University Press, Nueva York.

Stromberg, Peter G., 1993, Language and Self-Transformation. A Study of the Christian Conversion Narrative, Cambridge University Press, Cambridge.

Terán, Marta, 1995, iMuera el mal gobierno! Las reformas borbónicas en los pueblos michoacanos y el levantamiento indigena de 1810, tesis de doctorado en historia, El Colegio de México, México.

Torre, Renée de la, 2002, "El campo religioso, una herramienta de duda radical para combatir la creencia radical", en Revista Universidad de Guadalajara, núm. 24: Pierre Bourdieu en ocho perspectivas. Un homenaje, disponible en línea: <http://www.cge.udg.mx/revistaudg/ rug24/bourdieu5.html>. Consultado el 22 diciembre de 2013.

Torre, Renée de la y Cristina Gutiérrez Zúñiga, 2005, "Mercado y religión contemporánea”, en Desacatos. Revista de Antropología Social, núm. 18, pp. 9-11.

Velasco Santos, Paola, 2011, "Cambios, reacomodos y permanencias en San Andrés Cholula, Puebla: la construcción de una forma actual de ruralidad”, en Hernán Salas Quintanal, María Leticia Rivermar Pérez, Paola Velasco Santos (coords.), Nuevas ruralidades: expresiones de la transformación social en México, Universidad Nacional Autónoma de México, México. 